\title{
Morphology vs. Word Order in the Acquisition of V-to-I*
}

\author{
João Costa \\ João Loureiro \\ Universidade Nova de Lisboa \\ jcosta@fcsh.unl.pt \\ joao.loureiro@lycos.com
}

\begin{abstract}
This article presents an experiment on children's sensitivity to two phenomena associated with V-to-I: morphology and word order. It is shown that children are highly sensitive to morphology, but accept ungrammatical sentences in which verb and adverb are in the wrong order. These results on children's accuracy contrast with those reported for production. An analysis is proposed for explaining this asymmetry, discussing the notion of trigger in acquisition.
\end{abstract}

Key words: V-to-I, morphology, adverb, European Portuguese, trigger.

\section{Table of Contents}

\section{Introduction 4. Experiment on sensitivity}

2. The debate on V-to-I and morphology and the acquisition evidence to morphology and word order contrasts 5. Conclusions

3. Word order as the input for setting V-to-I in European Portuguese?

\section{References}

\section{Introduction}

The relation between morphology and syntax is a subject to a long debate. Part of the issue may be summarized as follows: is word structure a reflex of syntactic operations, as assumed by non-lexicalist hypotheses, or do words enter syntactic operations fully specified, acting as triggers for certain operations? This debate becomes particularly specific when one considers the relation between V-to-I movement and «rich» morphology. Since it is known that V-to-I syntactic movement and some specific type of inflectional morphology correlate, the issue is whether Vto-I movement is triggered by rich morphology, as proposed in Rohrbacher (1999),

* Research for this paper was partly sponsored by the project POCI/LIN/57377/2004, Fundação para a Ciência e Tecnologia. 
Vikner (1997), among others, or whether it is the factor that determines a certain type of morphological specification, as argued, for instances, in Halle and Marantz (1993) and Bobaljik (2000).

This debate is of great relevance for language acquisition, since it is legitimate to suppose that a trigger in the derivation correlates with a trigger for setting a parameter. In this specific case, if it is determined that V-to-I movement is the necessary condition for the existence of «rich» morphology, it is then legitimate to suppose that V-to-I movement is the relevant trigger for the acquisition of morphology. On the contrary, if for independent reasons, one establishes that a specific morphology triggers V-to-I movement, it may be the case that morphology is the relevant acquisition trigger for setting the value of this syntactic parameter.

The goal of this paper is to investigate Portuguese children's performance with respect to sensitivity to V-to-I and to morphology, in order to answer the following questions:

a) Does sensitivity to word order contrasts related to V-to-I precede, coincide or follow sensitivity to morphological contrasts?

b) Is it possible, based on sensitivity tests, to draw any conclusions concerning triggers for parameter setting?

c) Do such results directly enable drawing conclusions on the organization of the grammar?

The paper is organized as follows:

In section 2, we present the results of previous research by other scholars bearing on whether acquisition data play a role in the debate of whether V-to-I is a cause to or a consequence of rich morphology, showing that data from production appear to indicate that morphology cannot be the trigger for setting V-to-I.

In section 3, we show that, if word order facts are the relevant triggering experience for setting V-to-I, the data available for the acquisition of European Portuguese is rather complex and/or limited.

In section 4, an experiment is presented in which children's sensitivity to morphological contrasts and to syntactic contrasts relevant for setting V-to-I was tested. It is shown that children reveal a much higher accuracy in the morphological condition, in an apparent contradiction of the results discussed for production.

Section 5 presents the main conclusions of the paper.

\section{The debate on V-to-I and morphology and the acquisition evidence}

A substantial amount of work on the relation between V-to-I and morphology has been dedicated to identify the characteristics of verbal inflectional morphology in languages in which V-to-I movement exists (see Vikner 1997 and Koeneman 2000 for a summary of the proposals). Language acquisition data and, in particular, learnability issues are often used in the argumentation developed by several authors, since proposals must be made in such a way that the relevant morphological condition is learnable by the child acquiring V-to-I. 
In a review of the literature on the acquisition of V-to-I, Lardiere (2000) states that «developmental data from much child language acquisition research suggest that children know extremely early whether verbs raise or not in the language they are acquiring, almost certainly long before they've acquired the myriad relevant morphological distinctions required under either Rohrbacher's or Vikner's analysis» (Lardiere 2000, p. 106). Bobaljik (2002), defending a late insertion model, makes the interesting suggestion that the hypothesis that morphology is not a trigger for syntactic V-to-I movement does not necessarily mean that overt morphology does not act as a cue for setting a syntactic parameter, a matter we will return to in section 4. Nonetheless, based on observations regarding the late occurrence of morphological contrasts reported in Meisel (1993), Bobaljik (2002) casts doubt on the idea that knowledge of morphology precedes and acts as the necessary condition for the setting of V-to-I. According to this suggestion, the fact that children have a late mastery of verbal inflectional paradigms is problematic for the suggestion that such paradigms are the relevant cue for the child to discover whether the verb undergoes movement to I in his language. ${ }^{1}$

Following Bobaljik's reasoning, Gonçalves (2002) presents the results of her research on the spontaneous production of a Portuguese child, aged 2;00 (MLU$\mathrm{w}: 1,966)$, showing that, as reported in the acquisition of other languages, mastery of V-to-I precedes mastery of the verbal morphological paradigm. In particular, Gonçalves shows that verb placement with respect to negation ${ }^{2}$ and temporal adverbs is adult-like, tracing the existence of V-to-I movement.

As for morphology, Gonçalves (2002) shows that the same child exhibits $3^{\text {rd }}$ person singular as the preferred form, as summarized in (1):

(1) Data from one child (age: 2;0, $M L U$-w: 1.966):

3rd person singular: $\quad 44 / 71(61,9 \%)$

1st person singular: 10/71 $(14,1 \%)$

Non-finite: $\quad 7 / 71 \quad(9,8 \%)$

Imperative: $\quad$ 10/71 $\quad(14,1 \%)$

The data in (1) clearly show that the child has not fully acquired the verbal paradigm. More interestingly, Gonçalves (2002) shows that the child hesitates in verbal form, going from $1^{\text {st }}$ singular to $3^{\text {rd }}$ singular in self-reference in the same utterance, as illustrated in (2):

1. It must be noted that Bobaljik (2002) is cautious, stating that further research is needed in order to establish any causation relation in the acquisition of V-to-I and morphology.

2. It is not entirely clear whether the placement of negation in Portuguese is a clear diagnosis for V-to-I movement, a matter we will return to in section 3. 
(2) CHI: eu quer café

I wants-3sg coffee

"I want coffee"

CHI: eu quero café

I want-1sg coffee

"I want coffee"

CHI: eu quero

I want-1sg

"I want it"

FAT: o quê?

what?

"what?"

CHI: eu quer beber

I wants-3sg drink-Inf

"I want to drink"

It is important to note that the use of $3^{\text {rd }}$ person singular in this context is not a case of self-reference as usually found in child language, since the child is not referring to herself by using her name, but rather using the nominative $1^{\text {st }}$ person pronoun $e u$ (I). This piece of data is interesting for two different reasons: first, it shows that the child does make morphological errors, contrary to most claims in the literature that children are accurate in verbal agreement (for a synthesis, see Guasti 2002) ${ }^{3}$; second, as discussed by Gonçalves (2002), it may show that the child is not fully mastering the verbal paradigm, having hesitations in the use of $1^{\text {st }}$ person singular.

Elaborating on data of this type, Gonçalves (2002) concludes that morphology cannot be the triggering experience for setting V-to-I. Instead, the author argues that «there is good reason to suppose it is syntactic and/or pragmatic in nature».

Bearing these conclusions in mind, in the next sections, we will turn to an investigation of whether the trigger for setting V-to-I can, in fact, be syntactic.

\section{Word order as the input for setting V-to-I in European Portuguese?}

If, as suggested in Gonçalves (2002), word order is the relevant triggering experience for setting V-to-I, the first step to be taken is to determine which syntactic facts are to be analyzed as correlating with V-to-I movement.

Since the work of Emonds (1978) and Pollock (1989), the relative order of the verb with respect to adverbs, negation and floating quantifiers are taken as diagnoses for verb movement to the inflectional domain. In particular, if the verb precedes any of those elements, this signals the existence of V-to-I movement. We

3. In Gonçalves (2002), there is no data indicating how common this type of errors is. 
can therefore suppose that children are sensitive to such orders, since they are part of the relevant input for setting the correct value of V-to-I.

Additionally, it is important to note that Bobaljik (2000) shows that languages in which IP is split into T and Agr necessarily have V-to-I movement. Accordingly, other syntactic phenomena tracing the existence of two independent functional heads can be taken as criteria for knowing whether there is V-to-I, and consequently, as relevant triggering experience for the learner. For Bobaljik (2000), two relevant types of phenomena are transitive expletive constructions, and constructions showing the availability of two subject positions between CP and VP.

In what follows, we will consider each of these constructions and argue that only some adverbs may constitute a solid input for children.

\section{a) Transitive expletive constructions:}

European Portuguese does not have transitive expletive constructions of the type documented for Germanic. Therefore, this obviously cannot be part of the triggering experience for the learning child. At most, their unavailability might constitute negative evidence for positing that there is no V-to-I movement, which would obviously be wrong, since the language has V-to-I.

\section{b) Availability of two subject positions between $C P$ and VP:}

Bobaljik (2000) argues that when there are two subject positions between CP and VP, there is V-movement, since otherwise the verb would not be able to host the affix corresponding to the highest functional head. In Costa (2003), it is argued that there are two positions for the subject between CP and VP, namely Spec,Agr and Spec,T. However, it is shown that the latter can only be occupied in contexts of I-to-C, and, even then, it can only be detected if there is a high adverb tracing the position of the subject. The relevant configurations and examples are given in (3) and (4):

(3) a. $\left[_{\text {AgrP }} \mathrm{O}\right.$ Pedro $\left[_{\mathrm{TP}}\right.$ sempre/já $\left[_{\mathrm{TP}} \mathrm{t}_{\text {subj }}\right.$ tinha lido o livro. the Pedro indeed/already had read the book

b. * $\left[_{\mathrm{AgrP}}\left[_{\mathrm{TP}}\right.\right.$ sempre/já $\left[_{\mathrm{TP}}\right.$ o Pedro tinha lido o livro. indeed/already the Pedro had read the book "Pedro actually/already had read the book"

(4) a. $\left[_{\mathrm{CP}} \mathrm{O}\right.$ que $\left[_{\mathrm{C}}\right.$, tinha $\left[_{\mathrm{AgrP}}\right.$ o Pedro $\left[_{\mathrm{TP}}\right.$ sempre/já $\left[_{\mathrm{TP}} \mathrm{t}_{\text {subj }} \mathrm{t}_{\mathrm{v}}\right.$ lido...? what had the Pedro indeed/already read

b. $\left[_{\mathrm{CP}} \mathrm{O}\right.$ que $\mathrm{C}_{\mathrm{C}}$, tinha $\mathrm{C}_{\mathrm{AgrP}} \mathrm{I}_{\mathrm{TP}}$ sempre/já $\mathrm{T}_{\mathrm{TP}}$ o Pedro $\mathrm{t}_{\mathrm{v}}$ lido...? what had indeed/already the Pedro read "What had Pedro \{actually/already\} read?" 
In (3), it is shown that, in normal declarative sentences, the subject cannot appear to the right of TP-adjuncts, which can be understood as a ban on subjects surfacing in Spec,T. In (4), it is shown that the constraint banning subject in Spec,T is overridden whenever the inflected verb is in C. Leaving aside an explanation for the reasons behind the relation between the availability of Spec,T and the target of V-movement, ${ }^{4}$ what is relevant to emphasize is that the construction that attests two subject positions between $\mathrm{CP}$ and VP is quite complex, and, most importantly, arguably rare in the child's input, since it involves questions with I-to-C, rare in spoken language, and the presence of a specific subclass of adverbs. For these reasons, we will not consider this construction as relevant triggering experience for the learning child.

\section{c) Negation:}

Negation is not a valid criterion either for detecting V-to-I movement in European Portuguese. As argued in Matos (1998), negation is clitic-like and directly merged on the category hosting the verb. Of particular relevance is the fact, pointed out in Matos (1998), that negation accompanies the verb whenever it moves. For instances, in cases of I-to-C movement, the verb goes to $\mathrm{C}$ taking along the negation, as illustrated in (5):

O que não tinhas tu feito?

what not had you done

"What had you not done?"

This example shows that, when the verb moves, the negation is still preverbal, hence the traditional diagnostic for detecting verb movement (V-NEG order) is not valid in European Portuguese.

\section{d) Adverbs and floating quantifiers:}

As mentioned above, adverbs and floating quantifiers are traditional diagnoses for V-to-I movement. The availability of V-Adv and V-FQ orders (and the unavailability of the Adv-V and FQ-Adv counterparts) attests V-to-I movement. At this point, we would like to point out that, if this is the relevant triggering experience, it is quite unclear, since, for many adverbs, the two orders are available, as illustrated in (6):

(6) a. O Pedro frequentemente beija a Maria. the Pedro often kisses the Maria "Pedro often kisses Maria"

b. O Pedro beija frequentemente a Maria. the Pedro kisses often the Maria "Pedro often kisses Maria." 
Floating quantifiers behave alike:

(7) a. Os meninos todos leram o livro. the children all read the book

b. Os meninos leram todos o livro. the children read all the book "The children all read the book"

In Costa (1996) and Costa and Galves (2002), it is argued that this apparent optionality is a reflex of short verb movement in Portuguese: the verb undergoes movement, but not to the highest functional head. Note that the sentences in (6a) and (7a) are not to be analyzed as instances of subject left-dislocation or subject topicalization as proposed for similar orders in Italian in Belletti (1990), since the same orders can be found with quantified and negative subjects:

(8) Ninguém provavelmente leu o livro.

nobody probably read the book

"Probably nobody read the book"

It can be shown that V-movement is not optional in European Portuguese, since with certain adverbs only the postverbal position is possible. This is true for quantificational adverbs and for adverbs that are homophonous with adjectives:

(9) a. O João fala muito de sintaxe. the João talks much of syntax "João talks about syntax a lot."

b. *O João muito fala de sintaxe. the João much talks of syntax

(10) a. O João falou claro sobre a situação.

the João talked clear about the situation

b. *O João claro falou sobre a situação.

the João clear talked about the situation

It is important to note that, even manner adverbs, that are typically low, occurring postverbally, may surface preverbally, although associated with different interpretations. This is illustrated for the adverb mal (badly) in (11), which receives a proximative reading in preverbal position, and for estupidamente (stupidly) in (12), which is interpreted as subject-oriented in preverbal position:

(11) a. O João cantou mal o fado. (Manner)

the João sang badly the fado

"João sang the fado badly"

b. O João mal cantou o fado. (Proximative)

João badly sang the fado

"João almost didn't sing the fado". 
(12) a. O João respondeu estupidamente à pergunta. (Manner) the João answered stupidly to the question "João answered the question in a stupid way"

b. O João estupidamente respondeu à pergunta. (Subject-oriented) the João stupidly answered to the question "It was stupid of João to answer the question."

Coming back to the acquisition issue, what we are trying to show is that adverb placement may be a reliable criterion for detecting V-to-I, but, for the learning child, the only adverbs that provide relevant and unambiguous information are some manner adverbs, that cannot surface preverbally associated to different meanings, quantificational adverbs and adverbs that are homophonous to adjectives.

In conclusion, if one assumes that syntax is the relevant triggering experience for the child to set the V-to-I parameter, after a closer scrutiny of the data, one is led to conclude that the only compelling evidence is a limited set of adverbs that cannot appear between the subject and the verb. As for the other adverbs, the child might incorrectly conclude that V-movement is optional in European Portuguese. However, their accuracy in production of verb placement, documented in Gonçalves (2002), and referred to above, shows that this is not correct. ${ }^{5}$

It can be concluded from the discussion in this section that the relevant syntactic data that can function as experience for the child is not simpler than the mastery of a complete morphological paradigm. Therefore, it becomes legitimate to inquire what kind of information the child is sensitive to: to the relevant morphological information or to the relevant word order information?

In the next section, we report on an experiment conducted in order to test children's sensitivity to morphological contrasts and to the relevant word order contrasts.

\section{Experiment on sensitivity to morphology and word order contrasts}

\subsection{Research question}

The question we intend to address in this experiment is whether children are equally or distinctively sensitive to the relevant data that may constitute triggering experience for setting the V-to-I parameter. Moreover, it is our goal to check whether perception tests match the results reported in Gonçalves (2002) for production, namely accuracy in word order and partial failure in morphology. Three possibilities arise:

5. A reviewer suggests that the type of syntactic evidence the child is exposed to is confusing, which might cause a delay in the acquisition of V-to-I, and might predict a better performance on inflectional morphology. However, both the data reported in Gonçalves (2002) and in Santos (2003) on children's performance appear to contradict this suggestion, since in both studies, it is shown that children do produce constructions involving V-to-I in a systematic manner. 
a) Children are sensitive to word order contrasts, but not to morphological contrasts. If this turns out to be the result of the experiment, perception and comprehension match, and we have evidence to suppose that syntax, but not morphology, is the triggering experience for setting V-to-I.

b) Children are sensitive to morphological contrasts, but not to word order contrasts. Under this result, it is legitimate to suppose that morphological cues are the relevant triggering experience for setting the value of the V-to-I parameter. However, it has to be explained why perception and production differ.

c) Children are equally sensitive to morphological and word order contrasts. In this case, the test is inconclusive.

\subsection{Methodology}

We conducted a grammaticality judgement task with 11 Portuguese normally developing children aged between 3;01 and 4;00 (average age 3;05) and 6 adult controls. The task was designed as follows: the children were introduced to a foreign puppet and told that the puppet was trying to learn Portuguese. Their task was to tell whether the puppet was «saying things well» and, if they wanted, to correct him.

The conditions tested were:

a) Condition 1: Sensitivity to word order, through ungrammatical Adv-V orders (3 test items);

b) Condition 2: Sensitivity to finiteness, through ungrammatical sentences containing root infinitives ( 3 test items);

c) Condition 3: Sensitivity to person morphology, through ungrammatical sentences in which the verb and the subject failed to agree in person (3 test items);

d) Condition 4: Sensitivity to number morphology, through ungrammatical sentences in which the verb and the subject failed to agree in number (3 test items).

The tested sentences included only regular or high frequency verbs. The choice of adverbs for condition 1 took into account the conclusion that only certain adverbs are ungrammatical in the $\mathrm{Adv}-\mathrm{V}$ order, as discussed in the previous section. Examples of the test items are given in (13):

(13) a. Finiteness:

Eu cantar muito bem.

I sing-Inf very well

"I sing very well"

b. Person:

Eu moras na Quinta do Anjo.

I live-2sg at Quinta do Anjo

"I live at Quinta do Anjo" 


\section{c. Number:}

A minha mãe cozinham muito bem.

My mother cook-3pl very well

"My mother cooks very well"

d. Order:

A minha mãe rápido fez o jantar.

My mother quick made dinner.

"My mother made dinner quickly"

Eu muito mal canto os parabéns.

I very badly sing happy birthday.

"I sing 'happy birthday' badly"

In the experiment, 27 sentences were used: 3 per condition, 6 ungrammatical fillers and 9 grammatical fillers (these grammatical fillers included sentences of the type being tested, that is, sentences with the correct order in what concerns verb placement and correct verbal morphology). The experiment was preceded by an accommodation period, in which the children got acquainted with the puppet, and by a training period, for them to understand the task. Initially, 3 other children were tested, but they were discarded, since they did not understand the task.

\subsection{Results}

The results obtained are presented in the following manner: whenever the subjects correctly corrected the puppet, judging a sentence as ungrammatical, this behaviour was marked as «correct rejection»; if the subjects accepted an ungrammatical sentence, this was marked as «incorrect acceptance».

The following graph presents the results for the adult controls, divided by conditions.

As shown in Graph 1, adults revealed no problem with the task, correctly rejecting all the ungrammatical sentences.
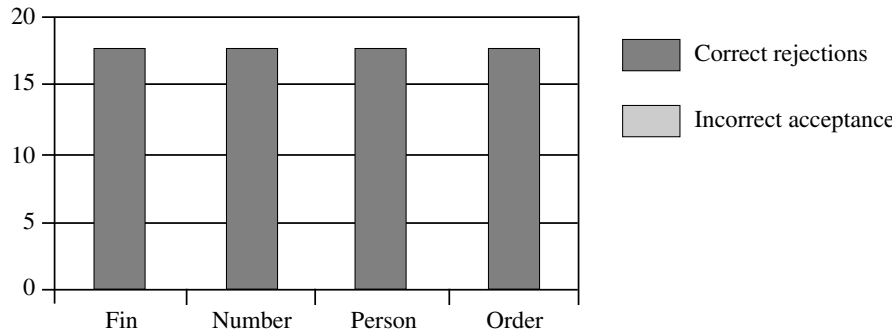

Graph 1. Results of the grammaticality judgement task for adult controls. 


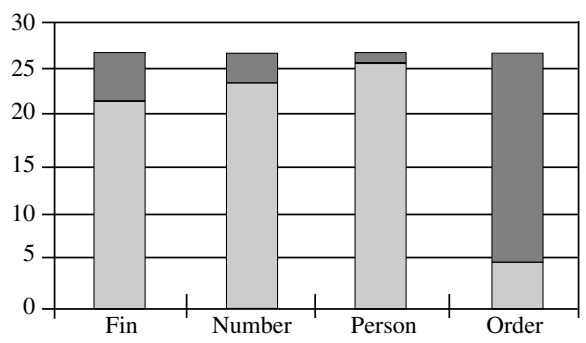

Incorrect acceptance

Correct rejections

Graph 2. Results of the grammaticality judgement task for children.

In Graph 2, we present the results of the test for the children, divided by condition.

As shown in Graph 2, children, unlike adults, fail to correctly reject the ungrammatical $\mathrm{Adv}-\mathrm{V}$ orders, but are quite accurate in rejecting the morphologically illformed sentences. No significant individual differences were found, and no effect of accuracy was found depending on the type of adverb used in the sentence for the word order condition. This contrast in behaviour becomes even more evident when all the morphological conditions are conflated, as shown in Graph 3.

The results presented above enable us to draw the following conclusions:

Correct rejections

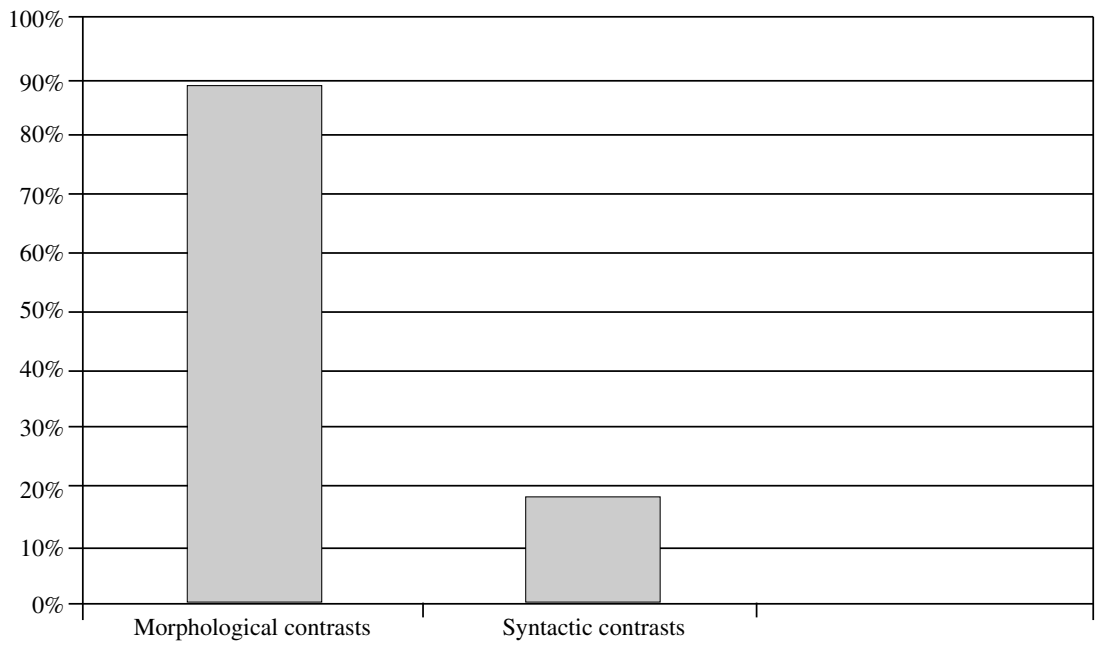

Graph 3. Correct rejections of ungrammatical sentences for children. 
a) Children are sensitive to morphological contrasts involving verbal inflection for all conditions tested: finiteness, person and number morphology;

b) Children are not sensitive to word order contrasts involving Adv-V orders. ${ }^{6}$

\subsection{Discussion}

The results obtained in the perception test reveal that children are more sensitive to the morphological facts under analysis in this paper than to the word order facts. As mentioned before, this contradicts the results reported for production in Bobaljik (2002) and Gonçalves (2002), which calls for an explanation, a matter we will return to shortly.

A first conclusion that may be drawn from the experiment is that it cannot be maintained that syntax is the relevant experience for setting V-to-I, since children, at an age in which V-to-I is acquired, are not sensitive to the only syntactic facts that might constitute positive evidence for the right setting of this parameter in European Portuguese. On the contrary, given their high accuracy in the morphological conditions, it is legitimate to suppose that morphology is the relevant trigger for setting V-to-I.

Let us now come back to the different results obtained for production, reported in Bobaljik (2002) and Gonçalves (2002), and in the perception test reported here. Putting it in simple terms, the difference may be summarized as follows: in production, accuracy in V-to-I precedes accuracy in the mastery of verbal morphology, while in the perception test accuracy in verbal morphology precedes accuracy in V-to-I. As pointed out in Bobaljik (2002), this discrepancy in results is only problematic if one conflates causation in synchronic grammar and chains of causation in acquisition. In other words, the fact that a certain type of data triggers the setting of a given parameter does not necessarily mean that the same type of causation is found in the derivation of a given representation. In the specific case of the relation between V-to-I and inflection, the different behaviours can be explained, if one assumes, along the lines of Halle and Marantz (1993) and Bobaljik (1995, 2000, 2002), that morphology follows syntax in the derivation of a sentence, although the trigger for setting the syntactic parameter is morphological in nature. In other words, according to this model, syntax feeds the morphological component. Morphology reads the output of syntax, and it makes sense that mastery of V-to-I precedes the acquisition of complete paradigms, since accuracy in production of the morphology implies knowing the output of syntax, and acquiring the rules internal to the Morphological component. Crucially, nothing in this model hinges on what the relevant triggers are in acquisition.

6. Children accepted the grammatical V-Adv orders, included as fillers, at a rate of $87 \%$. A reviewer suggests that this may indicate that children display knowledge of V-to-I, although incomplete. We are not sure that this can be the right interpretation, since, as shown for the condition with Adv-V orders, they tended to accept them. 
Based on these observations and on the data from the experiment, we then propose that the relevant trigger for setting V-to-I is morphological. ${ }^{7}$ The child is exposed to the relevant distinctions in the morphological paradigm, and correctly sets the value of the parameter. This early sensitivity is reflected in the accuracy in the perception of morphological contrasts. This will make the child move the verb in the syntax, which, in turn, is reflected by the accuracy in production of Vto-I. The low sensitivity to the word order contrasts reflects the fact that this is not the type of input that the children are paying attention to. In other words, although children produce V-to-I, they are not aware of the syntactic facts that lead them to do so. The good sensitivity to morphology gives them for V-to-I movement for free. The output of syntax enters the morphological component, but a complete mastery of morphological forms in the production is still dependent on the acquisition of other aspects of morphophonology (such as the acquisition of allomorphy and irregularities), which is reflected in a late accuracy in the production of certain verbal inflections.

\section{Conclusions}

This study shows that for a more complete understanding of the acquisition of inflection morphology in its relation with V-to-I movement, data from comprehension and production are needed. The good performance of children on perception of morphological contrasts reveals their early sensitivity to morphology. The asymmetry in the results obtained for production and in the experiment reported here enables establishing a crucial difference between triggers for parameter setting and derivational triggers. An open issue to be investigated (cf. Loureiro (in preparation)) is to determine when and under what conditions children attain adult-like performance in the task.

\section{References}

Belletti, A. (1990). Generalized Verb Movement. Turin: Rosenber and Telier. Bobaljik, J.D. (1995). Morphosyntax. Doctoral Dissertation, MIT.

- (2001). «The implications of rich agreement: why morphology does not drive syntax». Paper presented at GLOW 24, Universidade Minho, Braga, Portugal (April 9th, 2001).

7. As suggested by an anonymous reviewer, it may be the case that the trigger is morphological in part because the syntactic evidence is confusing or misleading, given the peculiarities of adverb placement discussed above. Indeed, we do not discard this hypothesis. As mentioned to us by Marit Westergaard (p.c.), in languages in which verb movement happens without a clear morphological correlate, as in dialects of Norwegian, it is expected that the word order cues are used by the children. It is then interesting to apply this type of experiment to children acquiring certain languages in order to find out whether their behaviour is different. Also, if the syntactic evidence is based solely on a specific subclass of adverbs, it will be interesting to investigate, in further work, whether there is any correlation between the results reported in this paper and children's comprehension of the relevant meanings of adverbs when they are placed in different positions. 
- (2002). «Realizing German Inflection: why morphology does not drive syntax». To appear in Journal of Comparative Germanic Linguistics.

Costa, J. (1996). Adverb Positioning and V-movement in English: some more evidence. Studia Linguistica 50:1, 22-34

- (2003). Null vs overt Spec,TP in European Portuguese. In J. Quer et al. (eds) Romance Languages and Linguistic Theory 2001, Amsterdam: Johns Benjamins, 31-47

- (2004). Subject Positions and Interfaces: the Case of European Portuguese. Berlin: Mouton de Gruyter

Costa, J. and C. Galves (2002). »External subjects in two varieties of Portuguese: evidence for a non-unified analysis». In C. Beyssade et al. Romance Languages and Linguistic Theory 2000, Amsterdam: Johns Benjamins, 109-125

Emonds, J. (1978). «The Verbal Complex V'-V in French». Linguistic Inquiry 9, pp. 151-175.

Gonçalves, F. (2002). «Comparing acquisition processes in Brazilian and European Portuguese - Additional evidence for morphology after syntax». In J. Costa and M. J. Freitas (eds.) Proceedings of the GALA 2001 Conference on Language Acquisition, Lisbon: Associação Portuguesa de Linguística, pp. 312-319.

Guasti, M.T. (2002). Language Acquisition. The Growth of Grammar. MIT Press, Cambridge.

Halle, M. and A. Marantz (1993). «Distributed Morphology and the pieces of inflection». In K. Hale \& J. Keyser (eds.), The View from Building 20: Essays in Linguistics in honour of Sylvain Bromberger, MIT Press, Cambridge, Mass, pp. 111-176.

Koeneman, O. (2000). The flexible nature of verb movement, Ph.D. Dissertation, University of, Utrecht.

Lardiere, D. (2000). «Mapping features to forms in second language acquisition». In J. Archibald (ed.). Second Language Acquisition and Linguistic Theory, Blackwell, Oxford, pp. 102-129.

Loureiro, J. (in preparation) MA dissertation, Universidade Nova de Lisboa.

Matos, G. (1998). «Negação frásica e concordância negativa em português europeu». In Actas do XIV Encontro Nacional da Associação Portuguesa de Linguística, Aveiro, pp. 197-218

Meisel, J. (1993). «Getting FAT: Finiteness, Agreement and Tense in early grammars». In Jürgen M. Meisel (ed.). Bilingual First Language Acquisition, John Benjamins, Amsterdam, pp. 89-129.

Pollock, Jean-Yves (1989). «Verb Movement, Universal Grammar and the structure of IP». Linguistic Inquiry, 20:365-424

Rohrbacher, B. (1999). Morphology-Driven Syntax: A theory of V to I raising and prodrop. John Benjamins, Amsterdam.

Santos, A.L. (2003). How children answer questions in European Portuguese. Paper presented at GALA 2003, Utrecht University.

Vikner, S. (1997). «V-to-I movement and inflection for person in all tenses». In L. Haegeman (ed.). The New Comparative Syntax, Longman, London, pp. 189-213. 